\title{
Research and Application of Computer Management of the Test Chemical Products Quality Analysis
}

\author{
Hairui Zhang $^{1 *}$, Guofu Zhang ${ }^{2}$ and Helin $\mathrm{Ye}^{2}$ \\ 1. School of Information Engineering, Lanzhou City University, Lanzhou 730070, China \\ 2. School of Chemistry \& Environmental Science, Lanzhou City University, Lanzhou 730070, China
}

\begin{abstract}
According to the regulations of the People's Republic of China national standard as the basis, on the part of chemical industry product quality inspection and analysis of the implementation of computer management has developed a set of software applications, the software in chemical products quality inspection and analysis of the means of management is an innovation. The software functions, can automatically process data, judge the product grade, quality analysis, objective and fair, convenient, fast, accurate, stable, practical, and easy to popularize.
\end{abstract}

Key words: Chemical products quality, analysis, automatic evaluation, software development, application.

\section{Introduction}

The development of computer technology, has brought great convenience and efficiency, information technology to people's work and life, only has become the preferred [1] to save the cost, improve work efficiency. With the deepening of the process of informatization construction of chemical products, the market competition pressure increases, the domestic chemical enterprises and its customers are particularly concerned about the quality of the information of chemical products, in order to carry out the system of management, production and sales of chemical products to track chemical product batch quality information. Analysis and test report of data processing and analysis of the chemical product quality brings the writing staff and managers a lot of inconvenience, not only inefficient, but also management errors and data loss because of careless. Therefore, in order to meet the needs of inspection and analysis of the chemical industry product quality, we will design and develop a system management software. The software will count test results, process

\footnotetext{
*Corresponding author: Hairui Zhang, lecturer, research fields: grid and cloud computing, software development. E-mail: zhanggf@lzcu.edu.cn.
}

data, automatically evaluate product specifications, print and save test results. It helps experimenters of enterprise to automatically handle product test data, save time, and improve work efficiency [2].

However, the existing management system of chemical product quality are independent of each other, it can't share the product data information, can't meet the needs of users, this paper develops a set of chemical product quality tracking system, chemical products integrated information system in the quality data information, meets the needs of users and enterprises.

\section{Research Content}

This study reveals the chemical quality of network management test method, test method and test analysis to analyze the project of chemical enterprises in the implementation of national standards as the basis, using inorganic chemical products as the main object, using organic chemical products for the secondary object, the analytic contents and principles are modelled on the national standard of the People's Republic of China [3], and instrument analysis method as the main line, using the visual basic language in chemical products quality inspection analysis program [4], to 
analyze the test data processing automation and networking. The realization of intelligent quality management of chemical products, improve the level of management, improve the quality of the product transparency, improve the economic benefit and social benefit, the software has the originality, practicality and advancement. The final goal of the software is to generate test report book automatically, access to basic information about products online, including: product name, company name, production date, production batches of products, product specifications (or level), inspector, responsible person analysis, etc.. The user through the computer network platform, detailed information can understand the desired product, in order to decide whether to buy the product. If you buy a product, but the product exist quality problems, you can directly negotiate or claim with manufacturer through the network, avoid the situation that cannot find the manufacturer or trek out to the manufacture. Chemical enterprises can sell their products to users through the network platform, to achieve information sharing, and ultimately achieve a win-win production between units and users. After the intelligent and network management of analysis and test report book, enterprise can track of the quality of products, and users and quality inspection departments can understand the quality and grade of products at any time. It can avoid the situation that the test conclusion of quality inspection department and other departments is inconsistent. Eliminate quality resort to deceit behavior. At the same time, to avoid the laboratory technician analysis report data unreal and results of treatment of inaccuracy in the process, put an end to the phenomenon of false data analysis and test, reduces the calculation and analysis of heavy work of laboratory test data analysis, improve the objectivity and impartiality of the examination data. The software can also according to the national standards, industry standards and enterprise standards the level range, the products are divided into grade one, grade two, grade three, grade defective. The computer can automatically judge the grades of products, automatic analysis of test date signed. The analyst and the person in charge as long as the analysis report book endorsement and signature.

\section{Development Environment and the Choice of Technology}

Key scientific problems in the software in the system classification and implementation of chemical products, software source code, the normal running of the software, create a network platform, to achieve the intelligent management.

\subsection{Development Environment and Architecture}

In the choice of development environment, the research group consider the running environment of stability, high efficiency, single machine operation and network operation, the most widely used windows platform for the system, the system uses C/S mode architecture (client/server), it can ensure the system's security and reliability, but also take into account the stand-alone operation and the network operation convenience and fluency of connection.

\subsection{Development Language: Visual Basic Language}

Visual Basic language was originally developed by the basic language development, but the change from Basic to Visual Basic is a qualitative leap. This change has not only greatly increased the functions of language, but also changed the programming mode, the type of programming interface and programming mechanism. So we use the Visual Basic 6 as a development tool.

\subsection{Database: Access}

Visual Basic 6.0 supports Access database, Microsoft Office Access is the database management system by microsoft released, which combines the microsoft jet database engine and the graphical user interface of two characteristics, is one of the components of the system microsoft office. Because 
the Access database system is mature, stable, reliable and simple, and a preferred database system in the development of small system.

\section{Conclusions}

(1) The user through the computer network platform, detailed information about the desired product, chemical companies can sell their products to users through the network platform, to achieve information sharing, and ultimately achieve a win-win production between units and users.

(2) After the intelligent and network management of analysis and test report book, enterprise not only can keep track of the quality of products, but also users and quality inspection departments to understand the quality and grade of products, provide products of the network information platform for the user. It can put an end to the phenomenon of false data analysis and test.

(3) Chemical products quality inspection report book analysis of network management is a major innovation, to provide scientific and effective means for the intelligent management of chemical enterprises, users, departments and quality inspection departments on the network which can save a lot of cost for the enterprise.

(4) To avoid the laboratory technician analysis report data unreal and results of treatment of inaccuracy in the process, put an end to the phenomenon of false data analysis and test, reduces the calculation and analysis of heavy work of laboratory test data analysis, as well improve the objectivity and impartiality of the examination data.

(5) The software has opened a new angle of view for computer application in chemical products quality inspection and management, to create advanced treatment methods, rapid, convenient, accurate, is a major breakthrough in the application of computer in chemical product quality. It has been widely used in all kinds of chemical enterprise, which can produce economic benefits, but also can produce obvious social and economic benefits, promote the wide application prospects.

\section{References}

[1] Zhang, H., Zhang, G., Zhang, Q., Cui, J., and Qi, J. H. 2014. "Computer Management of QuantitatiVe Analysia Chemistry Experiment.”. Journal of Chemistry and Chemical Engineering 8 (2): 176-179.

[2] Zhang, H., Zhang, G., Cui, J., Qi, J., and Lin, S. 2014. “In the Quantitative Analysis of Computer Application in Chemical Experiment." Journal of Gansu Teachers College 19 (5): 35-39.

[3] China Standard Press editor-in-chief. Chinese national standards (First Edition), Chinese Standard Press, 1983 August-1993 October.

[4] Zhu, C. 2005. Visual Basic Programming Tutorial. Beijing: Tsinghua University press. 